\title{
Separation of palm carotene from crude palm oil by adsorption chromatography with a synthetic polymer adsorbent
}

\begin{abstract}
Palm carotene was successfully concentrated from crude palm oil by a single-stage chromatographic process on a synthetic porous polymer. Carotene was concentrated to about $105 \mathrm{ppm}$ solution, which is about 160 times the original concentration in crude palm oil. Carotene recovery varied from 40 to $65 \%$ depending upon chromatographic conditions. The fatty acid composition of the palm oil did not change during the carotene recovery process, and the carotene composition was also almost the same as that in palm oil. Adsorption isotherms of the adsorbent differed from other adsorbents. This new recovery method for palm carotene may be suitable as an edible palm oil pretreatment process due to its efficient mass recovery of a valuable bioresource.
\end{abstract}

Keyword: Adsorption chromatography; Adsorption isotherm; Palm carotene; Palm edible oil; Synthetic porous resin 